\title{
MIASIS UTERINA
}

\section{Un caso de Miasis Uterina por Callitroga americana (Cushing y Patton, 1933)}

\author{
Laura Rojas R., M.D.* \\ Jaime Cantillo G., M.D.** \\ Ernesto Osorno-Mesa, M.D.***
}

\section{Introducción}

En las miasis las larvas pueden localizarse en cualquier sitio del cuerpo, pero la penetración en cérvix y endometrio es extraordinariamente rara; por considerar que entre nosotros es el primer caso, publicamos esta observación sobre el hallazgo, en el fondo de la cavidad uterina, de 3 larvas de Callitroga americana, en último estadio.

En la familia Calliphoridae hay varias especies causantes de miasis en el hombre y en los animales, pero el género más importante a este respecto, es Callitroga que encierra especies de distribución únicamente americana.

En este género $(1,2)$, dos especies, Callitroga americana y Callitroga macellaria por mucho tiempo se confundieron, porque las larvas de la primera solamente se desarrollan en tejidos sanos, no necrosados, mientras que las de la segunda se desarrollan en materia orgánica en descomposición o en tejidos animales necrosados. Las diferencias fundamentales para distinguir estas especies en estadio larvario se encuentran en las placas espiraculares (Foto $\mathrm{N}$ ! 1) y en la terminación de las tráqueas mucho más oscuras en C. americana que en C. macellaria (Foto $\mathrm{N}: 2$ ).

Las hembras de Callitroga americana son moscas de color azul verdoso con brillo metálico. El adulto varía entre 8 y $10 \mathrm{~mm}$. de longitud con tres rayas oscuras en el tórax. Cada hembra deposita de 10 a 400 huevos; las larvas nacen de 11 a 21 horas después de la postura, recién nacidas penetran inmediatamente en los tejidos vivos para alimentarse hasta llegar al último estadio larvario en una semana, al cabo de la cual se desprenden y caen al suelo (dependiendo de la localización) en donde pupan y emergen los adultos para comenzar nuevamente el ciclo evolutivo que de huevo a imago gasta dos semanas

* Profesora Asistente de Ginecología y Obstetricia, Facultad de Medicina, Universidad Nacional de Colombia.

** Profesor Asistente de Anatomía Patológica, Facultad de Medicina, Universidad Nacional de Colombia.

*** Jefe del Grupo de Entomología del Instituto Nacional de Salud Samper Martínez. 


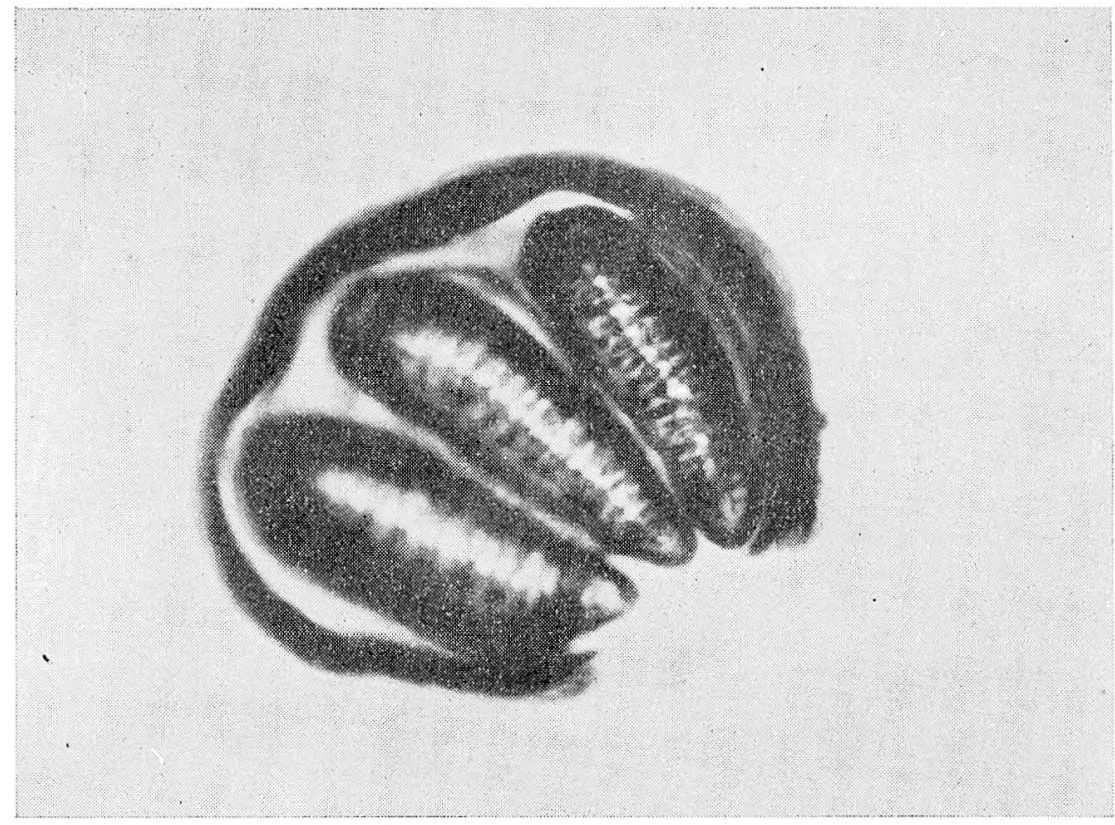

FOTOMICROGRAFIA No 1 - Placas espiraculares.

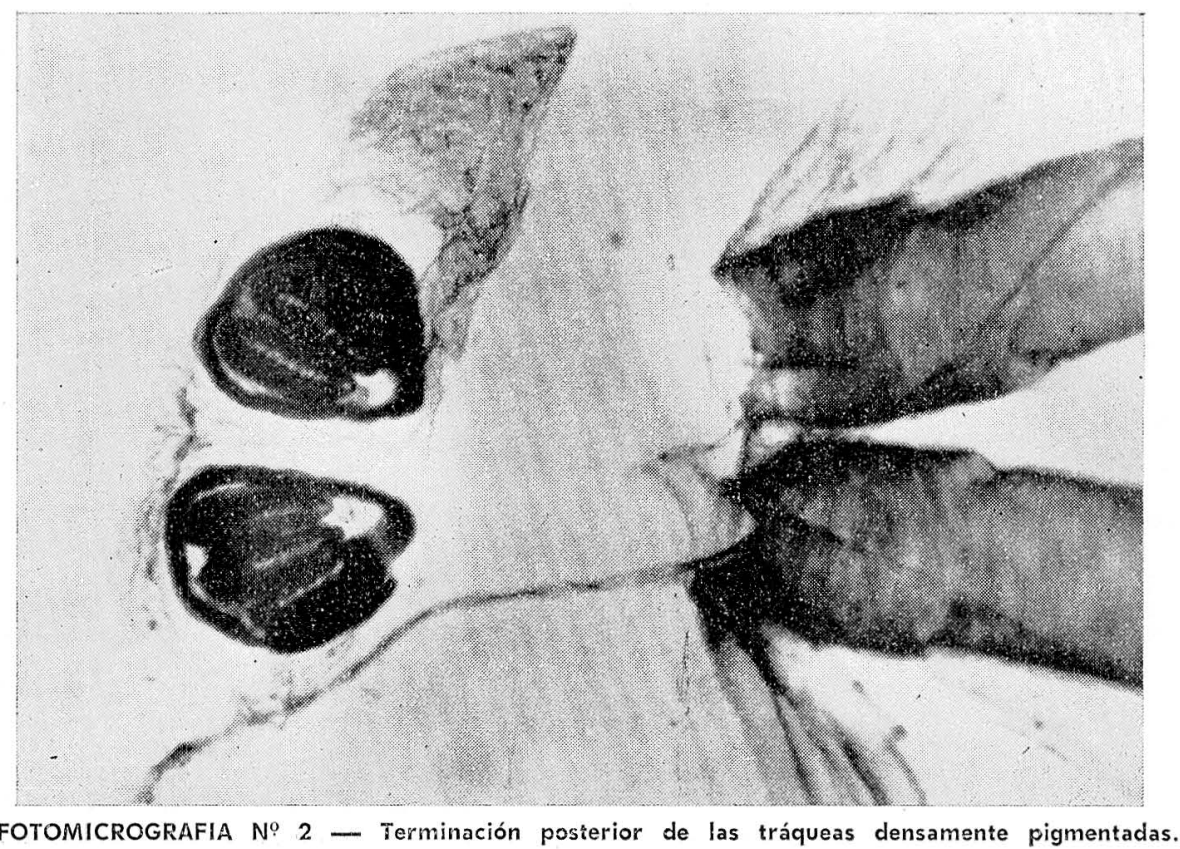


aproximadamente. Las hembras adultas son atraídas por los tejidos lesionados.

\section{RESUMEN DE LA HISTORIA CLINICA}

H. Clínica № 3.080

Edad: 38 años

Estado Civil: Casada

Natural y procedente de: FUSAGASUGA, Departamento de Cundinamarca.

Fecha de ingreso: Agosto 16-72.

Motivo de consulta: Sensación de cuerpo extraño en vagina, de larga evolución, pero anota qu desde hace 15 días, se ha acompañado de dolor.

Antecedentes patológicos: En varias ocasiones ha estado hospitalizada por parasitosis (Uncinarias, Tricocéfalos, Ascaris).

Pielonefritis y amigdalitis en 1957 y 1959 respectivamente.

G5 P5, último parto hace 6 años.

Examen físico: El examen físico fue normal. Solo se apreció prolapso uterino grado III, visualizándose cuello fétido, con gusanos en la superificie. Se ordenan duchas vaginales con creolina y acaroine.

Exámenes de laboratorio: Cuadro hemático: Hemoglobina 10.8 grs. Hematocrito $36 \%$, Leucocitos 8.800. Eosinófilos $4 \%$, Linfocitos $26 \%$. Segmentados $70 \%$. V.S.G. $51 \mathrm{~mm}$. a la hora. Colesterol 164 mgs.

Parcial de orina: Hematíes 3 a 5 por campo. Leucocitos: escasos. Coprológico: Coli + . Necator americano + .

Citología Vaginal: A-ll.

El 22 de Agosto se practica histerectomía vaginal por la técnica usual. La paciente evolucionó favorablemente y se dio de alta 10 días después.

Actualmente se encuentra en buenas condiciones.

\section{Anatomía patológica}

Protocolo quirúrgico № X-689-72.
Descripción macroscópica: La pieza consiste en un útero, que viene sin sus anexos, mide $10 \times 5 \times 5 \mathrm{cms}$. pesa 97 grs. el cérvix presenta una longitud mayor que la del cuerpo, mide $5.5 \times 5 \times 4.5 \mathrm{cms}$. el orificio exocervical es transversal $y$ se encuentra recubierto por un epitelio severamente engrosado, de aspecto corrugado y blanquecino. Se observan en el labio anterior varias y pequeñas ulceraciones. La unión escamocolumnar, asciende 2.2 ctms. al endocérvix. Al corte el estroma muestra congestión, la consistencia es blanda. El cuerpo uterino es piriforme, pequeño y hacia el fondo presenta varias adherencias fibrosas, que llegan hasta la parte superior de la cara anterior. El miometrio macroscópicamente es normal. La cavidad endometrial es triangular y mide de un ostio al otro 3.5 ctms. y de la mitad del fondo al orificio interno 4 ctms. En el fondo de la cavidad uterina se reconocen tres larvas de Callitroga americana, la mayor de las cuales mide 2 ctms. de longitud, la mediana 1.5 ctms. y la más pequeña 1 ctm. son de color grisáceo. La que está situada más profundamente en el endometrio se encuentra recubierta por una substancia blanquecina gelatinosa. El endometrio tiene un espesor de 0.5 ctms. (Fotos Nos. 3 y 4).

Descripción microscópica: Los cortes del cérvix muestran inflamación aguda y crónica severa, con queratinización exocervical y metaplasia escamosa. En el espesor del estroma cervical, se observan multitud de larvas rodeadas de infiltrado inflamatorio agudo y crónico donde predominan los eosinófilos. El endometrio es de tipo proliferativo y en él se observan varias larvas rompiendo el epitelio con sus ganchos y pene- 


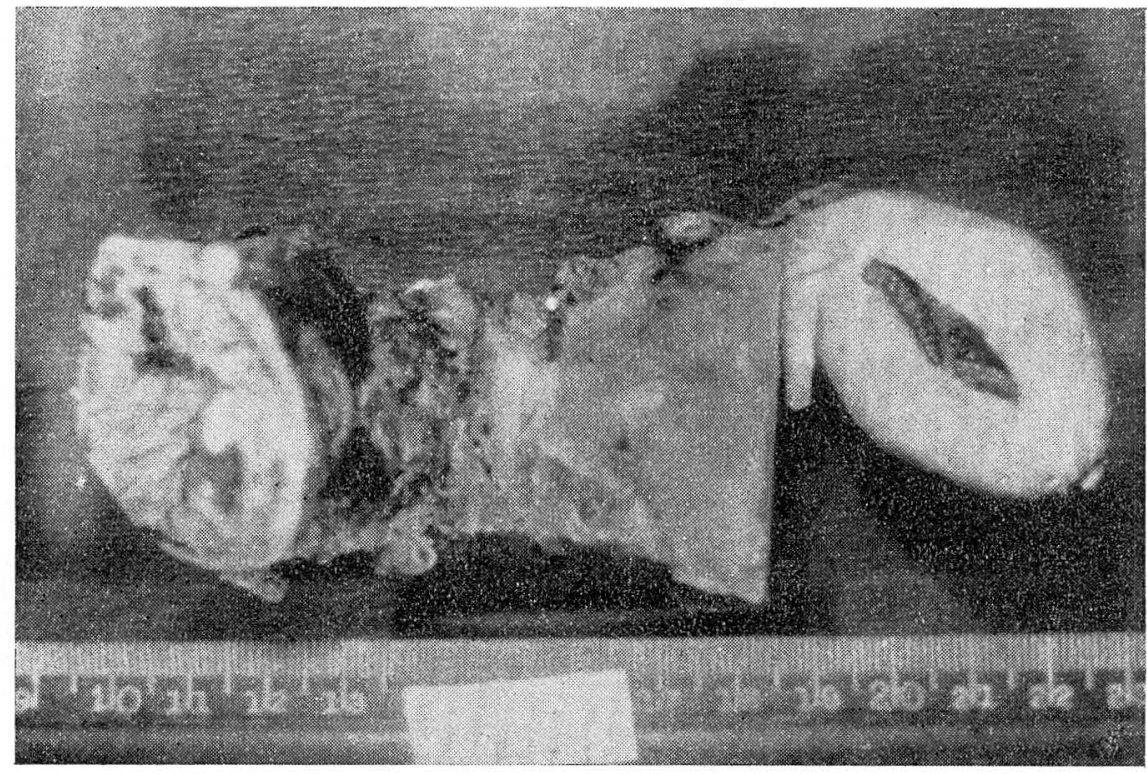

FOTO $\mathrm{N}^{0} 3$ - Larvas en el fondo de la cavidad uterina.

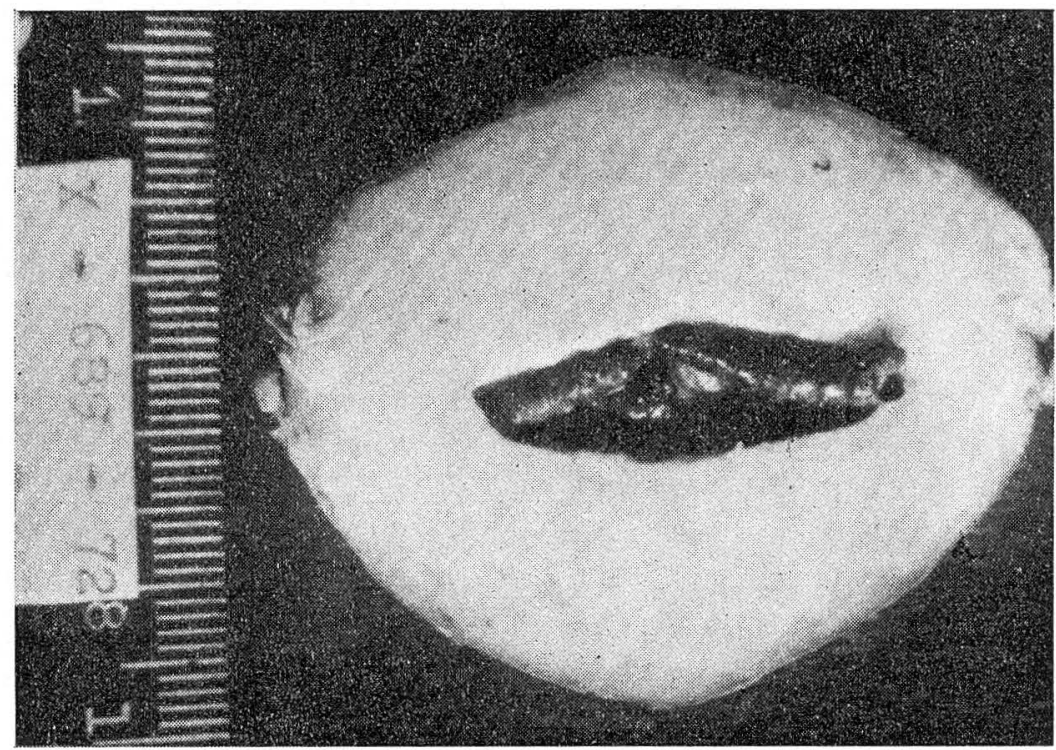

FОто № 4 - El fondo uierino donde se observan las larvas con mejor detalle. 
trando en dicha mucosa. Hay discreto infiltrado inflamatorio de tipo crónico. El miometrio es normal. (Fotos Nos. 5 y 6 ).

\section{Diagnóstico} CANA.

\section{MIASIS CERVICAL.}

MIASIS ENDOMETRIAL.,

CERVICITIS CRONICA CON JUERATINIZACION EXOCERVICAL Y METAPLASIA ESCAMOSA.

HISTERECTOMIA TOTAL POR MIASIS Y PROLAPSO GENITAL GRADO III.

La miasis en diferentes localizaciones del cuerpo humano ha sido encontrada por diversos autores en distintos países, pero no la hemos visto relatada en el útero humano.

Cantillo y Rojas en Colombia (3) en 1971 publican el primer caso de miasis vaginal por Dermatobia hominis o "nuche" en una mujer de 62 años. Hemos revisado los archivos del Instituto Materno Infantil (IMI), de Bogotá, hasta la fecha (Marzo de 1974), siendo el primer caso de miasis con localización en útero, teniendo este hospital un ingreso de 30.000 pacientes por año. El presente caso corresponde a una campesina procedente del Municipio de Fusagasugá. Esta población queda al Suroccidente de Bogotá con una altitud de 1.728 mts. sobre el nivel del mar y un clima de $22{ }^{\circ}$ C. La paciente ha vivido siempre en el campo. Por las malas condiciones socioeconómicas y por su prolapso es fácil entender la infestación de esta paciente, quien al hacer cualquier necesidad fisiológica, las moscas colocaron sus huevos en el cérvix prolapsado y comenzaron a desarrollarse penetrando al cuello y ascendiendo a la cavidad uterina, ori-

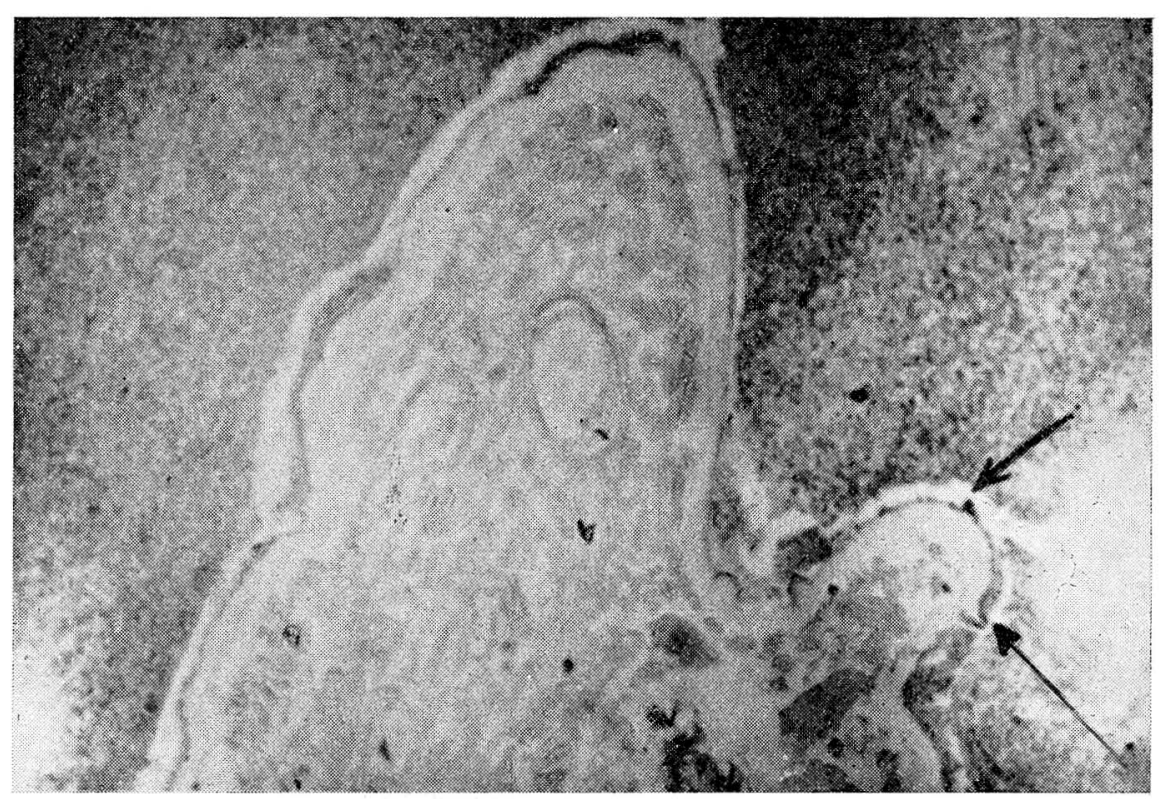

FOTO № 5 - Corte de cérvix donde se aprecia una larva en el espesor del órgano. Las flechas muestran las escleritas. 


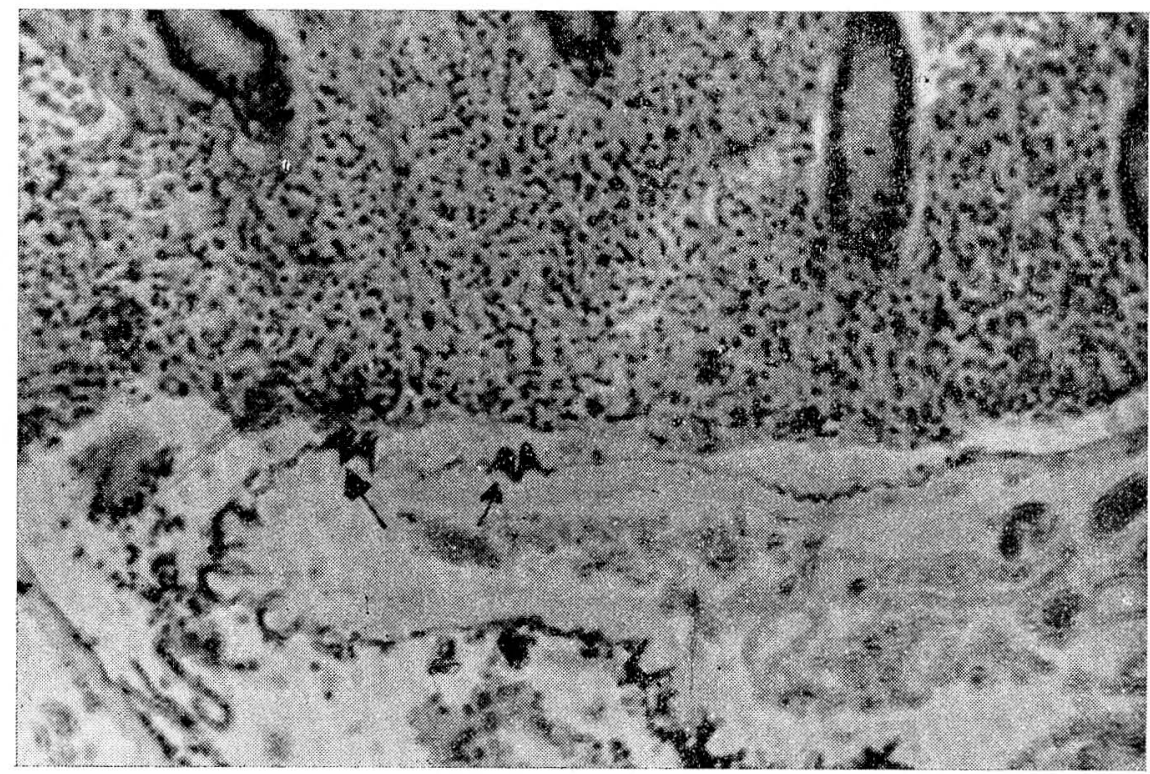

FОто $\mathrm{N}$ \% 6 - Corte del fondo uterino donde se aprecia otra larva.

Las flechas muestran algunas escleritas faríngeas de la larva en contacto con el endometrio.

ginando la sintomatología que la hace consultar al hospital. En la literatura que estuvo a nuestro alcance, no hemos encontrado ningún caso semejante.

\section{Resumen}

Se presenta el primer caso de miasis uterina en una mujer de 38 años con prolapso genital grado III. Se comprobó la presencia de 3 larvas de Callitroga americana en último estadio. Se estudió la morfología de una de las larvas. Se revisaron los archivos historiales del Instituto Materno Infantil, desde su funcionamiento (1927) hasta nuestros días (Marzo de 1974) y no se encontró miasis de localización uterina.

\section{Summary}

The first case of uterine miasis ap- pears in a 38 year old woman with a grade 111 genital prolapse. The presence of three Callitroga americana larvae in last stage was demonstrated. The historical records of the Instituto Materno Infantil, from its begining in 1927 up to date (March, 1974) were searched and no evidence was found on uterine location of miasis.

\section{BIBLIOGRAFIA}

1 PESSOA, S. B.: Parasitología Médica. 5a. edic. Ed. Livraria. Editora. Guanavara, Koogan, S. A., Río de Janeiro. pp. 1030-1032. 1958.

2 MATHESON, R.: Medical Entomology. 2 Ed. Ed. Comstock Publishing (Shring) Co. Inc. Ithaca, New York. pp 498-503. 1950.

3 CANTILLO J. y ROJAS L.: Miasis vaginal. (Dermatobia hominis o Nuche) Primer caso. Rev. Col. Obst. y Ginec. 22: 339, 1971. 